\title{
As relações entre conhecimento tácito e conhecimento científico a partir da base microeletrônica: primeiras aproximações
}

\section{Relations between tacit knowledge and scientific knowledge from a microelectronic base: first approaches}

\author{
Acacia Zeneida Kuenzer*
}

\begin{abstract}
RESUMO
Este artigo apresenta uma síntese dos resultados que vêm sendo obtidos com a pesquisa Reestruturação produtiva e novas formas de trabalho: o novo projeto pedagógico para a educação científico-tecnológica financiada pelo Plano Sul de Pesquisa e Pós-graduação/CNPq/Fundação Araucária, que tem por objetivo delinear as novas dimensões que passam a integrar a categoria competência a partir da introdução da base microeletrônica nos processos produtivos e sociais, com vistas à identificação dos princípios pedagógicos que devem orientar os projetos educativos que objetivam a inclusão dos que vivem do trabalho. ${ }^{1}$ Para tanto, será discutida a categoria competência tal como historicamente vem sendo construída nos modos taylorista/fordista e toyotista de organizar e gerir a produção, buscando compreender os seus limites e possibilidades para uma possível inclusão dos que vivem do trabalho, com particular destaque para a relação entre teoria e prática e entre conhecimento tácito e conhecimento científico. Finalmente, será apontada a
\end{abstract}

* Doutora em Educação pela PUC-SP, professora titular do Setor de Educação; professora e pesquisadora do Programa de Pós-Graduação em Educação da UFPR. acaciazk@uol.com.br

1 Pesquisa coordenada pela Doutora Acacia Zeneida Kuenzer, do Setor de Educação da Universidade Federal do Paraná, que integra os seguintes pesquisadores: Doutora Noela Invernizzi, do Setor de Educação/UFPR; Bolsistas Recém-Doutor Sonia Landini e Vidalcir Ortigara; bolsistas de IC Ana Carolina S. Duarte, Lúcia de Fátima Skrzypnik e Lidiane Lovatel; bolsistas de AT Sérgio A. Suckow e Ignácio G. Chaves. 
função mediadora da educação no estabelecimento de articulações entre trabalho e conhecimento.

Palavras-chave: conhecimento tácito, novas tecnologias e educação, relação teoria e prática.

\begin{abstract}
This article presents the synthesis of the results which have been obtained by the research on the Productive restructuring and new work ways: the new pedagogical project for the scientific-technological education. Such work has been financed by the South Plan of Research and Pos-graduation/CNPq/ Fundação Araucária, and it aims to outline the new dimensions that start making part of the competence category through the introduction of the microelectronic basis into the productive and social processes, focusing on the identification of the pedagogical principles that must guide the educative projects aiming the inclusion of the ones who live from the work. ${ }^{2}$ Thus, the competence category will be discussed in the same way it has historically been built through the taylorist/fordist and toyotist ways of organizing and administrating the production, searching for the understanding of its limits and possibilities for a possible inclusion of the ones who live from the work, and outstanding the relationship between theory and practice and between tacit and scientific knowledge. Finally, the mediation function of the education in the setting up of articulations between work and knowledge will be pointed out.

Key-words: tacit knowledge, new technologies and education, theory and practice relationship.
\end{abstract}

2 Research coordenated by Doctor Acacia Zeneida Kuenzer, from the Education Sector of Universidade Federal do Paraná, where the following researchers are integrated: Doctor Noela Invernizzi, from the Education Sector/UFPR; the holders of scholarships newlydoctors Sonia Landini and Vidalcir Ortigara; the holders of scholarships at IC Ana Carolina S. Duarte, Lúcia de Fátima Skrzypnik and Lidiane Lovatel; the holders of scholarships at AT Sérgio A. Suckow and Ignácio G. Chaves. 


\section{Introdução}

A retomada da categoria competência pelas políticas neoliberais de educação básica e profissional tornam necessário o estudo mais aprofundado do seu significado, com o intuito de buscar deslindar o cipoal de ambiguidades que têm revestido o debate pedagógico contemporâneo, cujos impactos já se fazem sentir sobre a qualidade dos processos educativos.

O ponto de partida para este estudo é admitir que o conhecimento é produzido a partir das relações sociais que os homens estabelecem em sua atividade real, enquanto produzem as condições necessárias à sua existência. É um processo coletivo que se dá ao longo do desenvolvimento das forças produtivas, resultante das múltiplas relações sociais que os homens estabelecem em sua atividade prática, através das quais apreendem, compreendem e transformam as circunstâncias ao mesmo tempo que são transformados por elas. ${ }^{3}$ É, portanto, um processo objetivo, embora necessariamente mediado pela subjetividade.

É esta forma de compreender o processo de produção do conhecimento que conduz à compreensão que competência é uma categoria enquanto expressa um conteúdo objetivo da realidade, ${ }^{4}$ através de formulações do pensamento humano que o apreende e sobre ele teoriza, limitado pelas condições materiais de compreensão da realidade em cada momento histórico. Assim compreendidas, as categorias são construtos parciais historicamente determinados, e neste sentido, expressões das bases materiais de produção que articulam, em cada estágio de desenvolvimento das forças produtivas, as dimensões objetivas e subjetivas que caracterizam o processo social de produção do conhecimento. Em decorrência, as categorias expressam as contradições inerentes ao modo de produção, e neste sentido, os limites e as possibilidades de avanço, tanto para o capital quanto para o trabalho.

Estudar a categoria competência, portanto, implica em apreender as suas conexões com as bases materiais de produção, que por sua vez demandam projetos político-pedagógicos que atendam à demandas de produção material e social da existência a partir das características de cada regi-

3 MARX, K.; ENGELS, F. A ideologia alemã. Lisboa: Martins Fontes, 1976.

4 KOPNIN, P. V. A dialética como lógica e teoria do conhecimento. Rio de Janeiro: Paz e Terra, 1978. p. 119. 
me de acumulação, como propõe Gramsci ${ }^{5}$ ao estudar a categoria princípio educativo. Não há, portanto, como tomar competência como uma categoria restrita ao campo da educação, porquanto ela expressa as demandas de formação humana a partir das bases materiais de produção. Por isto, este estudo busca apreender as especificidades que assume esta categoria nas diferentes formas de organizar e gerir o trabalho nos regimes rígido e flexível de acumulação.

\section{A categoria competência: alguns elementos para a sua compre- ensão a partir das bases materiais de produção}

Neste ítem, não se tem a pretensão de esgotar o estudo das conexões que se estabelecem entre as demandas das bases materiais de produção e as especificidades que vai assumindo a categoria competência ao longo da história, mas apenas pontuar as dimensões mais visíveis e já identificadas pela pesquisa, de modo a estimular o desenvolvimento de investigações de campo que permitam melhor elucidar como a relação entre trabalho e educação vai se construindo.

É importante destacar, ainda, que se está tomando como pressuposto que as formas históricas de organização e gestão da força de trabalho com vistas à realização da acumulação não se superam por substituição, mas sim por incorporação, gerando novas formas de combinação entre os setores dinâmicos e os precarizados, de modo a combinar diferentes modalidades de uso da força de trabalho que por sua vez demandam diferentes competências. A partir desta compreensão, os processos precários de desenvolvimento de competências através de projetos escolares e não escolares não representam um desvio, um problema a ser enfrentado, mas refletem a própria lógica de um regime de acumulação, cujos ganhos de produtividade são cada vez mais reduzidos. Assim, a competitividade passa a ser determinada, entre outros fatores, pelo uso desigual e combinado de competências na cadeia produtiva, através da incorporação de formas de consumo da força de trabalho próprias de regimes anteriores de acumulação e

5 GRAMSCI, A. Os intelectuais e a organização da cultura. Rio de Janeiro: Civilização, 1978. 
mesmo de modos de produção que se pensavam historicamente superados, como o trabalho infantil e até mesmo escravo, passando pelas distintas formas de uso precário.

As competências gestadas no taylorismo/fordismo, portanto, não são substituídas pelas demandadas pelas formas flexíveis de organização e gestão do trabalho, mas incorporadas em pontos da cadeia produtiva que não foram atingidos pela automação, combinação esta que passa a se constituir na estratégia para se obter ganhos de produtividade, e portanto, assegurar a competitividade.

Esta tese foi objeto de um texto produzido a partir da pesquisa, ${ }^{6}$ no qual se pretendeu demostrar que a relação entre trabalho e educação no regime de acumulação flexível se expressa através de uma diferente forma de materialização da dualidade estrutural que se constrói a partir da relação que se estabelece entre o mercado que exclui a força de trabalho formal para incluí-la de novo através de diferentes formas de uso precário ao longo da cadeia produtiva e um sistema de educação e formação profissional que inclui para excluir ao longo do processo, seja pela expulsão ou pela precarização dos processos pedagógicos que conduzem a uma certificação desqualificada.

Esta nova forma de dialetização entre trabalho e educação se constitui no princípio educativo do regime de acumulação flexível, no qual a categoria competência, ao expressar a sua materialidade, desempenha papel de reconhecida importância.

Feitas estas considerações, é possível delinear as especificidades que os modos de organizar e gerir o trabalho conferem à categoria competência.

A pesquisa que vem sendo desenvolvida desde 1995 em três empresas reestruturadas na Região Metropolitana de Curitiba, que desenvolvem processo descontínuos de produção (montagem) e mais recentemente em indústria do ramo petroquímico cujo processo é contínuo, e que passaram a incorporar novas tecnologias de produção e de gestão com vistas ao aumento de produtividade e de competitividade, permitem delinear as dimensões principais que conferem especificidade à categoria competência a partir dos modos de organizar o trabalho.

6 KUENZER, A. Exclusão includente e inclusão excludente: a nova forma de dualidade estrutural que objetiva as novas relações entre educação e trabalho. In: SAVIANI, D.; SANFELICE, J. L.; LOMBARDI, J. C. (Orgs.). Capitalismo, trabalho e educação. Campinas: Autores Associados, 2002. 
Assim é que se pode compreender a competência a partir das formas tayloristas/fordistas de organização e gestão do trabalho que se caracterizam por uma modalidade peculiar de divisão social e técnica do trabalho fundada na parcelarização, como

...um saber fazer de natureza psicofísica, antes derivado da experiência do que de atividades intelectuais que articulem conhecimento científico e formas de fazer. Neste sentido, o conceito de competência se aproxima do conceito de saber tácito, síntese de conhecimentos esparsos e práticas laborais vividas ao longo de trajetórias que se diferenciam a partir das diferentes oportunidades e subjetividades dos trabalhadores. Estes saberes não se ensinam e não são passíveis de explicação, da mesma forma que não se sistematizam e não identificam suas possíveis relações com o conhecimento teórico. ${ }^{7}$

A partir desta compreensão, pode-se afirmar que a competência se caracteriza no taylorismo/fordismo pelo seu caráter parcial e prático, o que explica as reduzidas exigências de escolaridade, e em conseqüência, de conhecimento teórico, para a sua construção, que decorre antes da experiência, principal requisito para a inserção dos trabalhadores no mundo do trabalho. Assim é que a pedagogia do trabalho tinha como instrutor um trabalhador experiente, que tutelava a aprendizagem dos novos trabalhadores, que tinham na observação, repetição e memorização as categorias do seu processo de aprendizagem, posto que não era necessário compreender e tão pouco intervir no processo para resolver problemas. Bastava saber fazer bem feito uma parcela do trabalho, o que ficava facilitado pelas tecnologias rígidas de base eletromecânica que determinavam o processo de fazer sem permitir a intervenção do trabalhador, e pela relativa estabilidade dos processos de trabalho, além de tudo bastante transparentes.

Daí a primazia do saber tácito sobre o conhecimento científico, da prática sobre a teoria, da parte sobre a totalidade, do descaso com a formação do profissional da educação, que também não mais fazia do que apresentar a sua prática para ser imitada.

7 KUENZER, A. Conhecimento e competências no trabalho e na escola. Boletim Técnico do SENAC, Rio de Janeiro, v. 28, n. 2, p. 3, maio/ago. 2002. 
No âmbito do trabalho, o processo educativo se reduzia ao desenvolvimento dos conhecimentos tácitos sobre determinadas partes do processo de trabalho, através da repetição dos procedimentos levados a efeito pelos trabalhadores mais antigos e pela própria experiência.

Os processos escolares reproduziam, de modo geral, esta concepção, objetivando a memorização de conteúdos compreendidos enquanto produtos do conhecimento humano, sobre os quais a inteligência do aluno não intervém; apenas observa, repete, memoriza e reproduz; os conhecimentos, requisitos para a execução de atividades práticas, nos cursos médios e superiores voltados para a formação profissional, eram ensinados na sua dimensão teórica durante a maior parte do curso; o espaço para supostamente aprender a prática, na sua dimensão de fazer, ocorria ao final do percurso formativo, através do estágio, ficando a articulação entre teoria e prática por conta do aluno.

De modo geral, a inserção no espaço laboral, através dos estágios ou do emprego, contemplavam a dimensão tácita do conhecimento, supervalorizando o saber fazer sobre o conhecimento científico e a parte sobre o todo, de modo a tornar corriqueira a denúncia dos alunos sobre a inutilidade da formação teórica, reproduzida pelos profissionais de recursos humanos que privilegiavam a experiência como critério de seleção.

As mudanças ocorridas no mundo do trabalho a partir da substituição da base rígida pela base flexível, através da mediação da microeletrônica, trazem impactos significativos sobre a concepção taylorista/fordista da categoria competência.

A chave para a compreensão desta passagem são os sinais de esgotamento das possibilidades do fordismo e do keinesianismo na contenção das contradições inerentes ao capitalismo, resultantes da rigidez do modelo: rigidez nos investimentos, nos mercados, na alocação e nos contratos de trabalho, nas posições dos sindicatos, nas relações entre estado, capital e trabalho expressas nas políticas públicas, nas formas de organizar e gerir o processo de trabalho, nas tecnologias de base física, e assim por diante. Para enfrentar os impactos negativos destas formas de rigidez sobre as taxas de lucro, as corporações viram-se obrigadas a desencadear um processo de racionalização, reestruturação e intensificação do controle sobre o trabalho, bem como investir em novas tecnologias, na automação, nas busca de novas linhas de produto e de nichos de mercado que permitissem rapidamente adequar a produção, qualitativa e quantitativamente, às demandas dos clientes. Surgem novas experiências na organização industrial e na vida social, que vão dar forma, na análise de Harvey, a um novo 
regime de acumulação, chamado por ele de flexível, que irá levar a novas relações entre a economia e o Estado, com profundos impactos sobre os trabalhadores e suas formas de organização.

A acumulação flexível, portanto, oriunda de um confronto direto com a rigidez do fordismo, apoia-se na flexibilização dos processos de trabalho, dos mercados de trabalho, dos produtos e padrões de consumo. ${ }^{8}$

Do ponto de vista dos impactos da flexibilização sobre a categoria competência, nos interessa em particular os resultados do acelerado processo de destruição e reconstrução de habilidades, sem deixar de levar em conta os demais aspectos levantados por Harvey: os níveis crescentes de desemprego estrutural, a redução dos salários e a desmobilização sindical. ${ }^{9}$

Deste ponto de vista, há que considerar as novas demandas de competência trazidas pela mediação da base microeletrônica a partir da flexibilização do regime de acumulação, em suas dimensões contraditórias.

Estas novas demandas, por sua vez, implicam no desenvolvimento de novas formas de disciplinamento da força de trabalho para atender às exigências da produção e da vida social, função esta atribuída aos distintos processos e modalidades de formação humana, escolares e não escolares, gerais ou profissionais; ao invés de profissionais rígidos, competentes nos fazeres que se repetem através da memorização, há que formar profissionais flexíveis, que acompanhem as mudanças tecnológicas decorrentes da dinamicidade da produção científico-tecnológica contemporânea.

Se do ponto de vista das formas de organização e gestão da força de trabalho através de procedimentos baseados no toyotismo o uso flexível da força de trabalho resulta em intensificação e precarização, ou seja, um uso cada vez mais predatório e desumano da força de trabalho, do ponto de vista dos processos educativos propostos para o desenvolvimento de competências há positividades que não podem ser desconsideradas. Talvez a mais importante delas seja a mudança de eixo na relação entre trabalho e educação, que deixa de priorizar os modos de fazer para contemplar a articulação entre as diferentes formas e intensidades de conhecimento, tácito e científico com foco no enfrentamento de situações não previstas.

Com base em Zarifian, ${ }^{10}$ pode-se afirmar que esta mudança de eixo, a partir da mediação da base microeletrônica com seus impactos nas formas

8 HARVEY, D. Condição pós-moderna. São Paulo: Loyola, 1992. p. 135-140.

9 HARVEY, op. cit., p. 141.

10 ZARIFIAN, P. Objetivo competência: por uma nova lógica. São Paulo: Atlas, 2001. p. $40-45$. 
de toyotistas de organizar o trabalho, se evidencia a partir da mudança na natureza do trabalho, que deixa de significar fazeres, para passar a significar intervenção quando os equipamentos ou sistemas apresentam comportamento anormal que exige atuação qualificada do trabalhador. Ou seja, como afirma o autor, o trabalho passa a significar enfrentar eventos, o que desloca o eixo da competência da memorização de procedimentos a serem repetidos para o enfrentamento de situações anormais, com maior ou menor grau de previsibilidade. No limite, competência passa a ser a capacidade para resolver situações não previstas, até mesmo desconhecidas, para o que se articulam conhecimentos tácitos e científicos adquiridos ao longo da história de vida, através das experiências de formação escolar e profissional e da experiência laboral. Mais do que à memorização, esta nova forma de conceber a competência remete à criatividade, à capacidade comunicativa, à educação continuada.

A partir destas mudanças se estabelece uma aparente contradição: quanto mais se simplificam as tarefas, mais se exige conhecimento do trabalhador, e não apenas tácito. Ao contrário, a crescente complexificação dos instrumentos de produção, informação e controle, nos quais a base eletromecânica é substituída pela base microeletrônica, passam a exigir

...o desenvolvimento de competências cognitivas complexas e de relacionamento, tais como análise, síntese, estabelecimento de relações, criação de soluções inovadoras, rapidez de resposta, comunicação clara e precisa, interpretação e uso de diferentes formas de linguagem, capacidade para trabalhar em grupo, gerenciar processos para atingir metas, trabalhar com prioridades, avaliar, lidar com as diferenças, enfrentar os desafios das mudanças permanentes, resistir a pressões, desenvolver o raciocínio lógicoformal aliado à intuição criadora, buscar aprender permanentemente, e assim por diante. ${ }^{11}$

Mesmo quando o trabalho é simplificado, o elevado custo de um investimento tecnologicamente sofisticado e as demandas de competitividade exigem trabalhadores potencialmente capazes de intervir crítica e criativamente quando necessário, não só assegurando índices razoáveis de produ-

11 KUENZER, A. Educação profissional: novas categorias para uma pedagogia do trabalho. Boletim Técnico do Senac, Rio de Janeiro, v. 25, n. 2, p. 19-29, maio/ago. 1989. 
tividade, através da observação de normas de segurança e da obtenção de índices mínimos de desperdício, de paradas, de retrabalho e de riscos, mas também otimizando o sistema.

O novo é que, se para o desenvolvimento de competências nas formas tayloristas/fordistas de organização e gestão do trabalho bastava a prática, agora não se prescinde do trabalho pedagógico escolar para o desenvolvimento das competências cognitivas complexas, que passam pela relação com o conhecimento sistematizado, a fim de aprender a trabalhar intelectualmente para desenvolver o raciocínio lógico formal, as capacidades comunicativas e a criatividade.

Neste modo de conceber a categoria competência a partir das demandas da acumulação flexível, é importante destacar que não desaparece a relevância do conhecimento tácito em nome da supremacia do conhecimento científico, mas sim se reestabelece a dialética entre teoria e prática, passando a competência a assumir dimensão práxica, como tem mostrado a pesquisa.

Em artigo recentemente publicado ${ }^{12}$ mostra-se que os operadores da Repar, refinaria onde vem se realizando a pesquisa, percebem, a partir de seu conhecimento tácito, a dimensão práxica da categoria competência bem como as relações que ocorrem no seu trabalho, entre teoria e prática, reconhecendo o papel e a importância destas dimensões que configuram a concepção de praxis e que se articulam embora guardem especificidades.

Esta forma de compreender a categoria competência levou ao seguinte entendimento, a partir das entrevistas com 144 operadores, levadas a efeito e sistematizadas por Invernizzi:

...capacidade de agir, em situações previstas e não previstas, com rapidez e eficiência, articulando conhecimentos tácitos e científicos a experiências de vida e laborais vivenciadas ao longo das histórias de vida. Ela (a competência) tem sido vinculada à idéia de solucionar problemas, mobilizando conhecimentos de forma transdisciplinar a comportamentos e habilidades psicofísicas, e transferindo-os para novas situações; supõe, portanto, a capacidade de atuar mobilizando conhecimentos..$^{13}$

12 KUENZER, Conhecimento e competências..., op. cit., p. 7-8.

13 Ibid., p. 8. 
A partir desta concepção, passou-se a compreender, como faz Vazquez, a prática como atividade, o ato ou conjunto de atos através dos quais o sujeito modifica uma matéria prima, independentemente de sua natureza, seja através do trabalho material ou do não material. Da atividade resultam produtos, materiais ou não materiais, que atendem a determinadas finalidades, de modo que o que a caracteriza é seu caráter real, sua materialidade. ${ }^{14}$

Já o trabalho intelectual se constitui como um movimento do pensamento no pensamento, que se debruça sobre a prática para apreendê-la e compreendê-la, de modo que não existe atividade teórica fora da prática, embora com ela não se confunda, posto que se atém ao plano do conhecimento ao produzir idéias, representações, conceitos. Em conseqüência de ser o trabalho teórico um processo de apropriação da realidade pelo pensamento, ele não é suficiente para transformar a realidade. Ou, como diz Vazquez,

A finalidade imediata da atividade teórica é elaborar ou transformar idealmente, e não realmente, para obter como produtos teorias que expliquem uma realidade presente ou modelos que prefigurem uma realidade futura. A atividade teórica proporciona um conhecimento indispensável para transformar a realidade (...) mas não transformam em si a realidade, a não ser quando apropriadas pela consciência individual e coletiva, e então se transformem as idéias em ações. ${ }^{15}$

A concepção que toma competência como praxis a partir das mudanças ocorridas no trabalho, portanto, remete à articulação entre teoria e prática, entre atividade e trabalho intelectual para atingir a uma finalidade, o que define o seu caráter transformador. Assim colocada a questão, tornase necessário melhor compreender o significado e as formas de articulação entre conhecimento tácito e conhecimento científico a partir da mediação da base microeletrônica.

14 VAZQUEZ, A. S. Filosofia da praxis. Rio de janeiro: Paz e Terra, 1968. p. 185.

15 Ibid., p. 203. 


\section{As formas de articulação entre conhecimento tácito e conheci- mento científico a partir da base microeletrônica}

O conhecimento tácito, como já se indicou anteriormente, é resultante da experiência no trabalho e praticamente se confunde com a concepção de competência no taylorismo/fordismo. O que se questiona é o papel que o conhecimento tácito passa a desempenhar a partir da implantação das novas tecnologias, em particular das que aumentam os níveis de automação.

A primeira necessidade que se coloca ao pesquisador é elucidar a permanência do conhecimento tácito nos processos automatizados, posto que há uma tendência a eximir as formas modernas de trabalho industrial de qualquer possibilidade de utilização de competência prática significativa. Contrariando esta tendência, Jones e Wood vão apontar para a necessidade de melhor compreender a relação entre conhecimento tácito e novas tecnologias, considerando que o conhecimento tácito se insere no âmbito das dimensões subjetivas do trabalho, formas inconscientes e geralmente não reconhecidas através das quais os trabalhadores, mesmo desqualificados, utilizam um saber com amplo poder de intervenção nos trabalhos prescritos. ${ }^{16}$

No taylorismo/fordismo é este saber que torna possível a execução das tarefas em face das diferenças entre trabalho prescrito e trabalho real, em razão do que o capital permanece em significativa dependência do trabalho, a partir do que se reforça o poder de negociação dos trabalhadores. Neste sentido, a automação, ao transferir para a máquina o trabalho e também o seu controle, permite ao mesmo tempo diminuir esta dependência, melhorar a confiabilidade do sistema e auferir ganhos de produtividade, em vista dos desafios da competitividade; e de quebra, diminuir o poder dos trabalhadores.

Resta saber se o sonho dourado do capitalista - a independência em relação ao conhecimento tácito - é possível a partir da automação. Tomaremos aqui três pesquisas que evidenciam o oposto, com a finalidade apenas de levantar hipóteses para a investigação acerca da relação entre conhecimento tácito e científico em face das novas tecnologias: a realizada por Jones e Wood sobre a relação entre qualificações tácitas e novas tecnologias;

16 JONES, B.; WOOD, S. Qualificações tácitas, divisão do trabalho e novas tecnologias. Sociologia du travail, n. 4, 1984. Tradução livre. 
a desenvolvida por Llory, que estuda o fator humano nos grandes acidentes industriais ocorridos na década de 80; a realizada por Dejours, também sobre as dimensões subjetivas do trabalho. ${ }^{17}$

Todos estes autores são enfáticos ao afirmar, a partir de extensos trabalhos empíricos, que o conhecimento tácito exerce influência vital sobre a introdução e sobre o funcionamento dos sistemas mediados pela base microeletrônica. Inicialmente, mostram Jones e Wood, a implantação de novas técnicas e equipamentos dependem do conhecimento existente, enraizado em uma prática anterior bem sucedida. ${ }^{18}$

Esta dimensão tem sido observada nas pesquisas realizadas na Região Metropolitana de Curitiba, através das entrevistas com os trabalhadores que acompanharam as mudanças tecnológicas ao longo do tempo, porém ainda na base eletromecânica; como as novas tecnologias guardavam relação com as precedentes, a transferência era crucial para a instalação e funcionamento dos novos equipamentos.

$\mathrm{Na}$ pesquisa em desenvolvimento no ramo petroquímico, embora este não tenha sido ainda um foco de investigação, os sistemas de controle automatizados, quanto à interface homem/máquina, não guardavam relação com as tecnologias anteriores; contudo, objetivavam o controle de um processo de trabalho, por suposto, amplamente dominado pelos operadores. Desta forma, o funcionamento do sistema de controle digital foi precedido de treinamento apenas na interface ho$\mathrm{mem} / \mathrm{máquina}$, ou seja, no domínio do novo processo de base microeletrônica, supondo que o conhecimento anterior, tácito e científico, fosse suficiente para assegurar confiabilidade na operação da unidade.

A partir desta suposição, não se priorizou a capacitação em teoria do processo, em segurança ou em manobras, dimensões estas que foram claramente impactadas pela implantação do novo sistema. A hipótese que se levanta, aqui, é a de que, a partir da implantação da nova base, os operadores demandavam conhecimento teórico de outra qualidade, não suprido pela relação decorrente da prática anterior entre conhecimento tácito e conhecimento científico. Esta hipótese decorrente

17 JONES; WOOD, op. cit; LLORI, M. Acidentes industriais: o custo do silêncio. Rio de Janeiro: Multiação, 2001; DEJOURS, C. Inteligência operária e organização do trabalho: a propósito do modelo japonês de produção. In: HIRATA, H. (Org.). Sobre o modelo japonês. São Paulo: Edusp, 1993.

18 JONES; WOOD, op. cit., p. 3. 
da identificação de indicadores que apontam nesta direção, está sendo investigada por Reis. ${ }^{19}$

Da mesma forma, ao acompanhar a implantação de uma nova unidade, sobre a qual não há experiência anterior, observou-se que o processo está sendo precedido de curso de formação corporativo, de estágios em indústrias que tenham implantado unidades similares, de cursos com os fabricantes do equipamentos e trabalho permanente e coletivo da equipe que vai pôr em funcionamento e assumir a operação da nova unidade, tendo em vista estudar o processo e desenvolver os procedimentos. Acrescese o cuidado da empresa em assegurar a presença de operadores e especialistas experientes de outras unidades no momento de pôr o sistema em funcionamento. Este caso conduz a análise em pelo menos duas direções: ao reforço da hipótese anterior, quando se supôs a necessidade de uma formação teórica de outra qualidade em decorrência da complexificação tecnológica; e, ao mesmo tempo a confirmação da indispensabilidade do conhecimento tácito no momento da "partida" da nova unidade.

A análise levada a efeito até aqui, permite formular uma nova hipótese para posterior discussão: o conhecimento tácito não desaparece com a implantação de novas tecnologias, em particular com as de base micreletrônica, mas muda de qualidade, passando a exigir maior aporte de conhecimentos científicos que não podem ser obtidos somente através da prática, senão através de cursos sistematizados.

Contudo, com relação ao funcionamento dos equipamentos e sistemas informatizados a partir da base microeletrônica, há necessidade de aprofundar as investigações, posto que o mero reconhecimento da relevância do conhecimento tácito é insuficiente para orientar o desenvolvimento de projetos pedagógicos.

Em primeiro lugar, há que se concordar com Jones e Wood quando afirmam que há diferentes elementos e graus de conhecimento tácito. O primeiro, e não o necessariamente mais simples de ser desenvolvido, diz respeito às práticas rotineiras, tanto mais eficientes quanto mais automatizadas, ou seja, quanto menos intervir a ação consciente. Do ponto de vista pedagógico, adentramos no campo das habilidades, onde a experiência é decisiva para a aprendizagem, secundarizando-se a compreensão teórica, a qual, se estiver presente, o será apenas no primeiro momento das explicações que se façam necessárias para iniciar o processo; neste caso,

19 REIS, M. A articulação entre conhecimento tácito e científico na operação de sistemas digitais: projeto de pesquisa. Curitiba: UFPR, PPGE, 2003. 
estamos no campo da automatização através da memorização de movimentos pela repetição, o que se constitui no elemento fundante da educação taylorista/fordista.

$\mathrm{Ou}$, como afirmam os autores citados, "para que se objetive a aquisição de um comportamento rotineiro adequado, ela deve ser um processo de integração de movimentos estandartizados e de redução de atos conscientes" ${ }^{20}$ Estas práticas rotineiras, tais como dirigir automóvel, pilotar avião, dançar, tocar um instrumento musical, fazer cálculos mentais, digitar, implicam em uma tal integração entre corporeidade e pensamento que permitam a realização de movimentos sem a necessidade do raciocínio. O processo de aprendizagem, neste caso, corresponde ao estabelecimento da relação estímulo/resposta.

Neste caso, a corporeidade passa a exercer papel fundamental, como mostra Dejours ao analisar o que chama de inteligência prática, que se distingue da inteligência cognitiva. Afirma o autor que a primeira característica da inteligência prática é estar enraizada no corpo. Assim é que os primeiros sinais de um evento (anormalidade) passam pelos sentidos, que acusam algum desconforto: um ruído, uma vibração, um cheiro, desde que exista uma experiência anterior comum à situação de trabalho. É esta dimensão corpórea que distingue a inteligência prática do raciocínio lógico; é o corpo, através da percepção, que orientará a ação, conferindo à inteligência uma direção, de modo a proceder a um rápido diagnóstico sucedido de intervenção, cuja temporalidade é inversa à de um raciocínio científico, que virá depois, para verificar, operacionalizar e disseminar a prática que lhe foi sugerida pela intuição. ${ }^{21}$ É desta forma que os operadores de refinaria, os pilotos de avião ou outros profissionais atuam, primeiro levando o sistema à uma condição segura, para depois verificar a melhor forma de retornar à normalidade.

A inteligência prática, assim concebida, implica em desconsideração e em alguns casos de desobediência ao trabalho prescrito, no todo ou em parte, bem como a conhecimentos técnicos e científicos; por isto, Dejours a chama de inteligência ardilosa, pois aqui o pensamento zomba do rigor. É o reino da malícia, da esperteza, da astúcia, do pensamento rápido.

Embora a inteligência prática seja fundamentalmente corpórea, não implica em ausência do pensamento, embora conduza a modelizações práticas e representações metafóricas do conhecimento técnico que não

21 DEJOURS, op. cit., p. 286. 
correspondem a cálculos ou aplicações rigorosas de procedimentos e instruções. ${ }^{22}$

Um bom exemplo desta afirmação encontrou-se em uma das empresas pesquisadas na Região Metropolitana de Curitiba, que montava placas de circuito impresso; as montadoras, com ensino fundamental completo, apesar do treinamento, substituíam os cálculos decimais por um sistema metafórico em que cada microcomponente recebia a denominação de um animal que sua forma lembrasse; em seguida, estabeleciam as regras de combinação entre os animais, livrando-se dos incômodos cálculos decimais, com eficiência; este sistema era rapidamente ensinado a cada nova operadora.

Assim, a inteligência prática está mais vinculada à obtenção de resultados do que ao conhecimento dos princípios e processos que servem de caminho ao pensamento; a questão posta é resolver rapidamente o problema, com economia de esforço e de sofrimento do corpo.

Finalmente, observa o autor, a inteligência ardilosa é criativa, fazendo surgir novas respostas, materiais, ferramentas, processos; e se faz presente em todos os homens, desde que estejam em boas condições gerais, e principalmente de saúde.

Embora se tenha inserido a concepção de inteligência prática ao discutir a dimensão rotineira do conhecimento tácito, isto não significa que a ela se restrinja; contudo, é na dimensão rotineira que a inteligência prática se manifesta de modo menos consciente, mais psicofísico, e onde melhor se explicita sua relação com a repetição, através da experiência. Esta forma de inteligência, nas demais modalidades de conhecimento tácito, vai se manifestar através de outra mediação, as ações intelectuais, em distintos níveis de articulação com a ação motora, em decorrência da complexidade do evento a ser enfrentado.

Uma segunda forma de conhecimento tácito identificada por Jones e Wood é aquela que demanda diferentes graus de tomada de consciência para tomar decisões em situações que fogem à normalidade; dependendo da complexidade da situação a ser enfrentada, são diferentes os níveis de consciência a mobilizar, podendo ocorrer necessidade de raciocínios bastante complexos. E, finalmente, apontam a terceira dimensão, que passa a desempenhar papel fundamental no toyotismo: as competências tácitas de natureza coletiva, derivadas da cooperação. ${ }^{23}$ Esta dimensão incorpora, se-

22 DEJOURS, op. cit., p. 288-290.

23 JONES; WOOD, op. cit., p. 6. 
gundo os autores, a tomada de consciência e julgamento dos trabalhadores, sobre como se insere o seu trabalho no processo de produção, considerando as interfaces com os trabalhos de seus companheiros de equipe.

Esta dimensão leva à necessidade da análise das relações que se estabelecem entre os conhecimentos tácitos no âmbito do trabalho coletivo, com suas diferenciações a partir de uma hierarquização reordenada pela mundialização do capital e pela reestruturação produtiva. Os fundamentos para esta discussão já foram apontados na primeira parte deste texto, quando se apontou a combinação desigual entre trabalhos com diferentes níveis de qualificação/precarização ao longo das cadeias produtivas, como constituinte da própria natureza da flexibilização. Se o setor reestruturado alimenta-se do precarizado para assegurar competitividade, prevalecendo a lógica da polarização das chamadas competências flexíveis nos setores mais tecnologicamente complexos da cadeia, se evidenciam diferentes combinações entre conhecimento tácito e científico, de modo que tanto mais se valoriza o tácito quanto mais se precariza o trabalho.

Decorre daí que a relação entre conhecimento científico e conhecimento tácito evidencia sua dimensão política, posto que se define a partir das possibilidades de diferentes combinações de estratégias de extração de mais valia ao longo da cadeia. É esta dimensão que faz importante o conhecimento aprofundado desta relação ao se pretender desenvolver processos educativos comprometidos com a emancipação dos que vivem do trabalho.

Embora não se desconheça a possibilidade, cotidianamente observada, do uso precarizado de força de trabalho qualificada, é inegável a relação entre investimentos em educação geral e qualificação profissional e as demandas de conhecimento científico ao longo das cadeias, posto ser este um significativo componente da estrutura de custos.

Uma questão que precisa ser melhor investigada é como se dividem estes custos entre o público e o privado, a partir da tendência da expansão pública apenas no ensino fundamental, passando os demais níveis serem expandidos pela iniciativa privada, e portanto, pagos pelo trabalhador; é sobre estes níveis efetivamente atingidos pela força de trabalho que o setor empresarial define suas estratégias de treinamento, sempre combinando os patamares educativos atingidos pelos trabalhadores e as necessidades da cadeia, como uma das estratégias de ajuste de custos. É neste sentido que se apontou, na primeira parte do texto, as novas formas de articulação entre educação e trabalho, com vistas à busca de equilíbrio entre as diferentes demandas de qualificação/precarização da força de trabalho. 
Resta saber qual é o limite imposto pelas mudanças ocorridas no mundo do trabalho para o uso de força de trabalho com formação científica, tecnológica e sociohistórica precária, o que vai contribuir para a definição das políticas públicas e privadas de educação dos trabalhadores.

Zarifian oferece elementos para uma análise mais consistente das dimensões anteriormente apresentadas ao introduzir o conceito de eventos (já citado), o qual merece tratamento mais detalhado. Também para este autor, só é possível compreender a emergência de um novo modelo de competências a partir das mudanças que vêm ocorrendo no mundo do trabalho. Dentre as dimensões por ele apontadas, o conceito de eventos é central. Mesmo considerando os diferentes níveis de automação dos sistemas industriais no mundo, o autor mostra que não é possível desconsiderar os efeitos da difusão da informática sobre as formas anteriores de trabalho. Assim é que a velocidade e o fluxo das máquinas ganham das "operações gestuais humanas e mesmo das operações intelectuais elementares". Consequentemente, se reposiciona a atividade humana, que deixa de se constituir em modos de fazer para enfrentar eventos, compreendidos como as ocorrências imprevistas, inesperadas, parcial ou totalmente, que perturbam o desenvolvimento regular da produção e não podem ser resolvidas pelas próprias máquinas através de sistemas de autocontrole. Estes eventos dizem respeito à todas às dimensões da produção, desde as panes às faltas de peças ou às encomendas repentinas e demandam capacidade de saber "inventar respostas que satisfaçam a um ambiente social complexo e instável". ${ }^{24}$

Em decorrência, nos sistemas automatizados, trabalhar passa a significar enfrentar eventos, ou seja, resolver problemas, o que impacta significativamente o desenvolvimento de competências, que passam a depender de mais conhecimentos e de habilidades cognitivas complexas, ou seja, do desenvolvimento da inteligência, diferentemente do que ocorre nos processos de trabalho que continuam mantendo as estratégias tayloristas/fordistas de organização e gestão. E para enfrentar eventos, é preciso estar em expectativa, pressentí-los, de onde continua a resultar importante a dimensão da corporeidade, ou psicofísica, como já se discutiu antes, posto que a percepção passa pelo refinamento da relação entre os sentidos e campo de trabalho; são ruídos dissonantes, cheiros, trepidações, cores, sabores, que repentinamente, para o trabalhador experiente, sinalizam a emergência de um evento. 
Esta análise remete a duas ordens de consideração sobre a relação entre conhecimento tácito e conhecimento científico; a primeira delas tem sido apreendida na Repar, onde se observou que os operadores que tinham reconhecida competência na operação do campo com os controles analógicos, mais facilmente enfrentam eventos após a implantação dos controles digitais, o que recoloca a relação positiva entre práticas anteriores e práticas mediadas pela base microeletrônica; ao mesmo, a avaliação levada à efeito com um grupo de operadores mostrou que metade deles estavam efetivamente preparados para enfrentar eventos que exigem a mobilização de competências complexas; neste caso, observou-se positiva relação entre domínio teórico e práticas de campo. Ao observar a forma como estes operadores resolviam as questões práticas apresentadas pela avaliação, sempre na perspectiva do enfrentamento de eventos, em muitas ocasiões com o uso do simulador, constatou-se a presença de uma competência práxica, que resultava de perceptível articulação entre os domínio teórico e prático.

Esta observação reforça a hipótese já enunciada, de que a base microeletrônica continua dependendo do conhecimento tácito para enfrentar eventos, mas que estes conhecimentos têm uma nova qualidade decorrente da necessidade de um maior aporte teórico, a par de uma consolidada experiência anterior para se desenvolver. Se isto, por um lado, mantém a relevância do conhecimento tácito, valorizando os trabalhadores, por outro põe os trabalhadores em maior dependência de conhecimentos científicos a serem obtidos através de processos formativos escolares e não escolares, o que é indicador de um cenário de crescente elitização, com o seu contrário: exclusão crescente de trabalhadores com reconhecida experiência anterior, mas precariamente escolarizados, o que dificultaria a sua requalificação.

Não é redundante afirmar que o conhecimento tácito não só não desaparece, mas renasce fortalecido e com uma nova qualidade com a base microeletrônica, nos setores tecnologicamente mais complexos das cadeias produtivas; esta nova qualidade repousa no estabelecimento de uma nova dialética entre trabalho manual e trabalho intelectual, trazida pelas novas tecnologias, a qual passa a demandar uma base anterior de conhecimento científico sobre a qual possa se desenvolver.

Como tendem a diminuir os postos de trabalho com esta característica, a decorrência será o aumento da precarização e da submissão do trabalho ao capital nos setores menos dinâmicos das cadeias produtivas, aumentando as diferenças entre os trabalhadores, cuja maioria fica cada vez mais desprotegida. 
Por um lado, submetidos aos trabalhos mais precários e com grande mobilidade, grande parte dos que trabalham não têm a possibilidade de desenvolvimento de um conhecimento tácito que valorize a sua força de trabalho nos momentos de negociação. Por outro, a banalização das competências, no sentido de sua simplificação, ao permitir que praticamente qualquer pessoa possa aprender a fazer qualquer coisa com um rápido treinamento, não conduz a processos educativos escolares e não escolares mais prolongados, que permitam acesso ao conhecimento teórico articulado às práticas laborais.

As conclusões de Dejours e de Llory, nas obras já citadas, encaminham a análise na direção do estabelecimento desta nova dialética entre trabalho intelectual e trabalho prático. Dejours vai mostrar que a inteligência prática não se manifesta apenas na esfera do trabalho manual, estando presente em todas as tarefas e atividades:

...ela encontra-se também no centro da atividade intelectual, e mesmo do trabalho teórico (...) na atividade do pesquisador (...) a engenhosidade, os ardis da inteligência, (...) fazem-se notar na arte da demonstração, nas malícias, na elegância, às vezes no estilo, que se conjugam na parte retórica de todo discurso teórico e científico. ${ }^{25}$

Portanto, o caráter mais intelectualizado do enfrentamento dos eventos não secundariza o conhecimento tácito, mas o recoloca sobre novas bases, posto que passa a requerer maior mobilização das competências cognitivas complexas, aí incluída a capacidade de criação. Ainda nesta linha, Dejours vai afirmar que na base das descobertas científicas, incluindo os processos experimentais, encontra-se uma boa e sólida base de inteligência prática. ${ }^{26}$

Llory, ao analisar os grandes acidentes industriais da década de 80 a partir do senso comum que coloca o fator humano como o elo fraco dos sistemas técnicos avançados, vai concluir exatamente o oposto: é no e pelo trabalho cotidiano e graças à atividade e ao savoir-faire dos agentes em todos os níveis, que a maioria dos acidentes latentes não se tornam acidentes ativos. ${ }^{27} \mathrm{Na}$ análise dos casos realizada no corpo da obra, o autor vai mostrar

26 Ibid., p. 288.

27 LLORY, op. cit., p. 21-36. 
que, quando os controles automatizados falham, ou quando o planejador do sistema de controle não previu proteções para um dado evento, o controle dos acidentes depende do conhecimento dos trabalhadores, ou seja, do fator humano. Esta conclusão é no mínimo contraditória com os estudos referentes aos equipamentos técnicos e à segurança das instalações, do ponto de vista da confiabilidade. Segundo estes estudos, o fator humano é considerado sempre a partir de um ponto de vista pejorativo, atribuindo-se os erros à displicência, inconsequiência, falta de responsabilidade, incompetência; e, em decorrência, concentram as estratégias de confiabilidade nos fatores técnicos, transferindo para os sistemas de controle todas as proteções possíveis.

Esta estratégia decorre da suposição da fragilidade do fator humano, que deverá, sempre que possível, ser substituído por dispositivos técnicos de segurança. ${ }^{28}$ Contudo, se as pesquisas mostram que, quando os sistemas não funcionam, a confiabilidade depende da subjetividade dos trabalhadores que lhes permite inventar soluções que tragam o sistema para a condição segura, evitando acidentes, como desenvolver este conhecimento tácito se as experiências cotidianas, que se constituem no fundamento das aprendizagens e das suas transferências para novas situações são cada vez mais inviabilizadas pela automação?

É preciso considerar que a restruturação produtiva é um fenômeno recente, que se deu sobre a base taylorista/fordista onde o exercício laboral permitia um número maior de experimentações passíveis de transferência para novas situações, e também entre os trabalhadores. Com a desmobilização destes trabalhadores ao longo do tempo, e com a inserção dos novos trabalhadores nos novos sistemas informatizados, como se desenvolverá o conhecimento tácito?

Neste ponto está-se trabalhando com uma hipótese oposta à anteriomente enunciada: será suficiente o conhecimento científico, sem a base anterior da experiência de campo, que dá a conhecer o processo de trabalho a ser controlado?

Reis, em sua pesquisa, encontrou indicadores que permitem trabalhar com esta hipótese, a partir de conversas informais de cunho exploratório, quando obteve depoimentos que mostram que os entrevistados construíram seu saber tácito a partir das amplas e diversas possibilidades de experimentações no campo e nos painéis analógicos, que permitiam mais freqüentes e mais diversas intervenções no processo, com o que se sentem melhor preparados para enfrentar eventos. 
A partir destas constatações, o que o autor indaga é qual o grau de confiabilidade de um operador que passe diretamente a operar controles digitalizados sem ter passado por estas experiências, observando que no atual sistema os eventos são mais complexos? Se, em decorrência do avanço tecnológico, os equipamentos estão crescendo em confiabilidade e o número de intervenções é menor, como desenvolver as competências teórico-práticas necessárias ao enfrentamento de eventos sem o apoio na experiência?

A ansiedade dos operadores quanto a esta questão foi identificada por Araújo ${ }^{29}$ quando realizou entrevistas em uma indústria petroquímica exatamente no momento de implantação do sistema digital de controle. Naquele momento, muitos operadores antigos, e experientes, estavam se aposentando ou deixando a empresa através do plano de demissões voluntárias, na metade da década de 90 . A pesquisadora registrou a ansiedade dos operadores exatamente com relação à insegurança no manuseio do novo sistema decorrente da pouca experiência com o sistema anterior aliada à perda do capital cultural dos que deixavam a empresa. E, ao mesmo tempo, a insegurança decorrente da terceirização da manutenção, fato que se insere na mesma ordem de discussão.

$\mathrm{Na}$ mesma linha de análise, Reis ${ }^{30}$ reporta práticas do passado em que foram encontrados operadores que desenvolveram um conhecimento tácito de natureza eminentemente experimental, baseada no ensaio e erro, relativo à interface homem/máquina, o que vale dizer: sabem como proceder, mas não conhecem cientificamente os controles computadorizados.

Poderá a confiabilidade dos sistemas automatizados depender deste tipo de conhecimento tácito? Parece que aqui estamos na contramão das conclusões de Llory, o que pode ser assim sintetizado: é este operador capaz de intervir em eventos complexos, em situações imprevistas, ou quando os controles enviam informações incorretas ou ainda quando as proteções não funcionam? Talvez sim, porém isto é satisfatório como critério de confiabilidade?

Nos defrontamos, portanto, com as conseqüências pedagógicas decorrentes de se conceber competência enquanto praxis: se o conhecimento tácito é insuficiente para assegurar confiabilidade aos sistemas de base microeletrônica, também o é o conhecimento científico, recolocando-se

29 ARAÚJO, E. A educação para a saúde dos trabalhadores no contexto da acumulação flexível: estudo de um setor de uma refinaria de petróleo. Curitiba, 1999. Dissertação (Mestrado) - Universidade Federal do Paraná.

30 REIS, op. cit. 
aqui a necessidade de se considerar o caráter da ação educativa, enquanto ação mediadora entre a teoria e a prática para o desenvolvimento de projetos pedagógicos que invistam no desenvolvimento das dimensões de positividade inerentes ao trabalho humano, que articulam subjetividade e objetividade.

\section{A função mediadora dos processos educativos}

As novas relações entre conhecimento tácito e conhecimento científico a partir das mudanças decorrentes da base microeletrônica trazem novos desafios para a educação dos que vivem do trabalho.

O ponto de partida para esta discussão é a constatação que, de posse do conhecimento científico, o conhecimento tácito se desenvolve; a recíproca, porém, não é verdadeira, como apontam os operadores entrevistados na pesquisa já citada, ${ }^{31}$ que passam a reivindicar conhecimento científico para melhor responder aos eventos, constatando que sua prática não é suficiente; ou seja, a prática, por si não ensina, a não ser através da mediação da ação pedagógica. São os processos pedagógicos intencionais e sistematizados, portanto, que mediando as relações entre teoria e prática, ensinarão a conhecer. Não basta, portanto, inserir o trabalhador na prática, para que ele espontaneamente aprenda,

...é preciso considerar que a prática não fala por si mesma; os fatos práticos, ou fenômenos, têm que ser identificados, contados, analisados, interpretados, já que a realidade não se deixa revelar através da observação imediata; é preciso ver além da imediaticidade para compreender as relações, as conexões, as estruturas internas, as formas de organização, as relações entre parte e totalidade, as finalidades, que não se deixam conhecer no primeiro momento, quando se percebem apenas os fatos superficiais, aparentes, que ainda não se constituem em conhecimento. ${ }^{32}$

31 KUENZER, Conhecimento e competências..., op. cit., p. 8.

32 Id. 
A realidade, as coisas, os processos, são conhecidos somente na medida em que são criados, reproduzidos no pensamento e adquirem significado; esta re-criação da realidade no pensamento é um dos muitos modos de relação sujeito/objeto, cuja dimensão mais essencial é a compreensão da realidade enquanto relação humano/social. Ou seja, o ato de conhecer não prescinde do trabalho intelectual, que é um movimento do pensamento que não se desenvolve espontaneamente, precisando ser aprendido:

...o ato de conhecer não prescinde do trabalho intelectual, teórico, que se dá no pensamento que se debruça sobre a realidade a ser conhecida; é neste movimento do pensamento que parte das primeiras e imprecisas percepções para relacionar-se com a dimensão empírica da realidade que se deixa parcialmente perceber, que, por aproximações sucessivas, cada vez mais específicas e ao mesmo tempo mais amplas, são construídos os significados. ${ }^{33}$

Ensinar a conhecer, enquanto capacidade de agir teoricamente e pensar praticamente é a função da escola; e este aprendizado não se dá espontaneamente através do contato com a realidade, mas demanda o domínio das categorias teóricas e metodológicas através do aprendizado do trabalho intelectual.

As novas demandas de articulação entre conhecimento científico e conhecimento tácito reforçam a escolarização em níveis cada vez mais ampliados e com maior qualidade como condição necessária à inserção e permanência nas relações sociais e produtivas para os que vivem do trabalho.

Esta constatação leva a rechaçar, de pronto, as alternativas que têm sido oferecidas pelas políticas públicas ao trabalhadores: educação profissional chamada básica, independente de escolarização anterior, que não possibilitam sequer o desenvolvimento de conhecimento tácito com a qualidade necessária para a inserção em ocupações menos precarizadas.

As pesquisas que vêm sendo realizadas no âmbito deste projeto, permitem apontar com segurança que a inclusão, resolvido o problema da oferta de ocupações, só será possível mediante o domínio dos conhecimentos científicos, tecnológicos e sociohistóricos que estão na base de

33 KUENZER, Conhecimento e competências..., op. cit., p. 8. 
constituição da sociedade contemporânea, a ser viabilizados, no mínimo, por uma boa escolarização fundamental e média. A partir daí será possível, no trabalho ou em cursos de formação escolares, desenvolver competências de cunho mais específico para atender a demandas específicas de setores da produção.

Causa espanto, portanto, ao tempo em que as pesquisas levem a estas constatações, que as políticas públicas em vigor para todos os níveis de ensino proponham como tarefa à escola o desenvolvimento de competências entendidas como capacidades de realizar tarefas práticas, desvalorizando, e mesmo declarando desnecessário, o conhecimento científico. Assim é que se traduzem as competências no ensino médio, na educação profissional e nos cursos de graduação, onde os percursos curriculares tendem a ser encurtados, à luz do princípio pós-moderno que nega a objetividade da ciência e o caráter histórico da produção do conhecimento, ao mesmo tempo que ampliam os espaços da prática, na esperança que a mera inserção do aluno no processo de trabalho seja suficiente para a sua formação.

Retrocede-se, assim, ao princípio educativo do taylorismo/fordismo, onde o melhor instrutor era o "Tonicão", que embora não conhecesse a ciência do seu trabalho, tinha virtuosidade nas práticas laborais, desenvolvida ao longo do tempo através de sua experiência. Ele também não sabia ensinar, porque conhecimento tácito não se sistematiza, e portanto, não se explica; mas tinha imensa boa vontade em se deixar observar e em mostrar como fazer, pois ele "sabia na prática".

O problema é que as novas formas de trabalho aos poucos vão fazendo desaparecer os Tonicões, as tarefas vão perdendo seu conteúdo através da simplificação dos processos de trabalho pela automação, os tempos de permanência nas ocupações são cada vez mais curtos, a rotatividade dos trabalhadores por ocupações as mais diversas aumenta. Sem espaço para desenvolver conhecimentos tácitos e sem acesso ao conhecimento científico, os trabalhadores precarizados engrossam cada dia mais as filas do desemprego, sem esperança de inserção.

Neste contexto, resta perguntar a quem interessa reduzir o espaço da escola ao espaço do conhecimento tácito, desqualificando o único local onde os trabalhadores poderiam ter acesso ao conhecimento científico, tecnológico e sociohistórico, enquanto produto do pensamento humano, mas também enquanto método para aprender a conhecer?

Não se trata, contudo, de retroceder a práticas pedagógias teoricistas, de longa data questionadas, mas também não há como sustentar o 
pragmatismo utilitarista que tem se traduzido em práticas pedagógicas espontaneístas com freqüência cada vez maior. Trata-se, portanto, de repensar os processos pedagógicos, para que a escola de fato estabeleça a mediação entre conhecimento e práticas sociais, entre teorias e práticas, de modo a intencionalmente assumir a sua função de introduzir os homens e mulheres nas ações relativas ao conhecer e ao produzir conhecimentos, tácitos e científicos, tendo em vista a construção de uma outra sociedade, sobre bases mais justas e igualitárias.

\section{REFERÊNCIAS}

ARAÚJO, E. A educação para a saúde dos trabalhadores no contexto da acumulação flexível: estudo de um setor de uma refinaria de petróleo. Curitiba, 1999. Dissertação (Mestrado) - Universiade Federal do Paraná, PPGE.

DEJOURS, C. Inteligência operária e organização do trabalho: a propósito do modelo japonês de produção. In: HIRATA, H. (Org.). Sobre o modelo japonês. São Paulo: Edusp, 1993.

GRAMSCI, A. Os intelectuais e a organização da cultura. Rio de Janeiro: Civilização, 1978.

HARVEY, D. Condição pós-moderna. São Paulo: Loyola, 1992.

JONES, B.; WOOD, S. Qualificações tácitas, divisão do trabalho e novas tecnologias. Sociologia du travail, n. 4, 1984.

LLORI, M. Acidentes industriais: o custo do silêncio. Rio de Janeiro: Multiação, 2001.

KOPNIN, P. V. A dialética como lógica e teoria do conhecimento. Rio de Janeiro: Paz e Terra, 1978.

KUENZER, A. Conhecimento e competências no trabalho e na escola. Boletim Técnico do SENAC, Rio de Janeiro, v. 28, n. 2, maio/ago. 2002.

. Educação profissional: novas categorias para uma pedagogia do trabalho. Boletim Técnico do Senac, Rio de Janeiro, v. 25, n. 2, p. 19-29, maio/ago. 1999.

. Exclusão includente e inclusão excludente: a nova forma de dualidade estrutural que objetiva as novas relações entre educação e trabalho. In: SAVIANI, D.; SANFELICE, J. L.; LOMBARDI, J. C. (Orgs.). Capitalismo, trabalho e educação. Campinas: Autores Associados, 2002. 
MARX, K.; ENGELS, F. A ideologia alemã. Lisboa: Martins Fontes, 1976.

REIS, M. A articulação entre conhecimento tácito e científico na operação de sistemas digitais: projeto de pesquisa. Curitiba: UFPR, PPGE, 2003.

VAZQUEZ, A. S. Filosofia da praxis. Rio de janeiro: Paz e Terra, 1968.

ZARIFIAN, P. Objetivo competência: por uma nova lógica. São Paulo: Atlas, 2001.

Texto recebido em 25 maio 2003

Texto aprovado em 05 set. 2003 